\title{
A suicide gene approach using the human pro- apoptotic protein tBid inhibits HIV-1 replication
}

\author{
Peter M Huelsmann ${ }^{1 \dagger}$, Andreas D Hofmann ${ }^{1 \dagger}$, Stefanie A Knoepfel ${ }^{1}$, Jasmin Popp ${ }^{2}$, Pia Rauch', \\ Francesca Di Giallonardo ${ }^{3}$, Christina Danke ${ }^{2}$, Eva Gueckel ${ }^{4}$, Axel Schambach ${ }^{5}$, Horst Wolff ${ }^{6}$, Karin J Metzner ${ }^{1,3^{*}}$, \\ Christian Berens $^{2^{*}}$
}

\begin{abstract}
Background: Regulated expression of suicide genes is a powerful tool to eliminate specific subsets of cells and will find widespread usage in both basic and applied science. A promising example is the specific elimination of human immunodeficiency virus type 1 (HIV-1) infected cells by LTR-driven suicide genes. The success of this approach, however, depends on a fast and effective suicide gene, which is expressed exclusively in HIV-1 infected cells. These preconditions have not yet been completely fulfilled and, thus, success of suicide approaches has been limited so far. We tested truncated Bid (tBid), a human pro-apoptotic protein that induces apoptosis very rapidly and efficiently, as suicide gene for gene therapy against HIV-1 infection.
\end{abstract}

Results: When tBid was introduced into the HIV-1 LTR-based, Tat- and Rev-dependent transgene expression vector pLRed(INS) ${ }_{2} R$, very efficient induction of apoptosis was observed within 24 hours, but only in the presence of both HIV-1 regulatory proteins Tat and Rev. Induction of apoptosis was not observed in their absence. Cells containing this vector rapidly died when transfected with plasmids containing full-length viral genomic DNA, completely eliminating the chance for HIV-1 replication. Viral replication was also strongly reduced when cells were infected with HIV-1 particles.

Conclusions: This suicide vector has the potential to establish a safe and effective gene therapy approach to exclusively eliminate HIV-1 infected cells before infectious virus particles are released.

\section{Background}

Both basic and clinical science can greatly benefit from vectors that induce cell death in a temporally and spatially controlled manner. Inducible death vectors do not only contribute to determining the precise effect of specific cells on behavior [1], development [2], and disease [3,4], they can also provide critical tools for treatment of many diverse diseases, including adoptive immune transfer, cancer therapy, atherosclerosis, stem cell transplantation, or viral infection [5-10]. Enzymes and toxins of bacterial or viral origin are frequently used to kill the targeted cells. However, they are not necessarily the best choice for all applications, due to complications that can arise from

\footnotetext{
* Correspondence: Karin.Metzner@usz.ch; cberens@biologie.uni-erlangen.de † Contributed equally

${ }^{1}$ University of Erlangen-Nuremberg, Institute of Clinical and Molecular Virology, Erlangen, Germany

${ }^{2}$ University of Erlangen-Nuremberg, Department Biology, Erlangen, Germany Full list of author information is available at the end of the article
}

immune responses [11], cell cycle dependence [12], and bystander killing [13]. Ectopic expression of endogenous pro-apoptotic proteins is an attractive alternative, because they should be non-immunogenic, they initiate a wellestablished cellular program [14,15], and their target cells are frequently primed for apoptosis $[16,17]$.

The pro-apoptotic proteins most often used in such applications are caspases $[7,8,18,19]$ and members of the Bcl-2 family, like BimS [20], Bax [21,22], or truncated Bid (tBid; BH3 interacting domain death agonist) [23-25]. tBid is generated by cleavage of Bid through activated caspases- 2 and -8 , granzyme $B$, and cathepsins. Translocation of tBid to the mitochondria leads to the release of cytochrome $\mathrm{c}$ resulting in the activation of apoptosisinducing caspases [26-28]. Transient or inducible expression of tBid leads to rapid and efficient induction of apoptosis in a variety of cell lines [23-25].

Thus, this pro-apoptotic protein represents a promising candidate for a suicide gene therapy that aims at

\section{Ciomed Central}


specifically eliminating cells infected by human immunodeficiency virus type 1 (HIV-1) before infectious viruses are produced. An infection with HIV-1 is still incurable despite constant improvements to antiretroviral therapy which dramatically reduced the mortality rate of HIV-1-infected patients [29]. Unfortunately, a substantial fraction of these patients still experiences therapy failure and/or serious side effects due to the treatment. This is often accompanied by the emergence of drug-resistant viruses [30]. Thus, improving the existing approaches and finding new antiretroviral strategies remains a major challenge in the fight against HIV-1. Numerous suicide genes have already been tested, for instance, Bax [21], protein kinase R [31], caspase-3 [18], the host shut-off protein of herpes simplex virus [32], diphtheria toxin A [33,34], and barnase [35]. However, most of them were either not efficient enough and/or cell death was not induced fast enough ultimately resulting in insufficient inhibition of HIV-1 replication. The kinetics observed and the very low protein concentrations needed to induce cell death by tBid [23] would fulfill two major requirements of a successful suicide gene: Efficiency and immediacy.

Another obstacle to this approach is the basal activity of the HIV-1 LTR promoters used, which led to unspecific cell death of HIV-1 uninfected cells [34,36,37]. The new retroviral vector pLRed(INS) 2 R utilizes three distinct elements originating from HIV-1 to more stringently regulate transgene expression: i) It contains the $5^{\prime}$ and 3' HIV-1 LTR, so that efficient gene expression requires HIV-1 Tat [38]; ii) the vector comprises the HIV-1 Rev-responsive element (RRE) leading to Revdependence for mRNA transport from the nucleus to the cytoplasm [39]; and iii) two HIV-1 inhibitory sequences (INS) of the gag gene are incorporated into this vector further enhancing the dependency on Rev in terms of mRNA export significantly [40]. This vector fulfills the criterion of HIV-1 specificity and, consequently, provides a safe gene therapy vector.

Here, we replaced the reporter gene dsRed in the improved HIV-1 indicator plasmid pLRed(INS) ${ }_{2} \mathrm{R}$ [40] with the very potent suicide protein tBid. The resulting suicide vector was highly dependent on HIV-1 Tat and Rev for target gene expression. It very efficiently and rapidly induced apoptosis in vitro before infectious viruses were released from the HIV-1 infected cell and, therefore, provides a promising gene therapy approach against HIV-1 infection.

\section{Results}

tBid induces efficiently and rapidly cell death in HeLa SS6 cells

To estimate the susceptibility of the cell line HeLa SS6 towards induction of cell death by the human pro- apoptotic protein tBid, we transiently co-transfected these cells with the plasmid pCMV-tBid which constitutively expresses tBid under control of a CMV-promoter, and with pEGFP-C1 allowing us to determine transfection efficiencies by measuring green fluorescence. 24 hours after transfection, GFP was expressed in $63 \%$ of the HeLa SS6 cells (Figure 1A). This number increased to $>90 \% 48$ hours after transfection (data not shown).

tBid induced cell death in $~ 97 \%$ of the HeLa SS6 cells within 24 hours after transfection with pCMV-tBid and in $\sim 94 \%$ of pCMV-tBid/pEGFP-C1 co-transfected cells (Figure 1A). Similar results were obtained in two additional independent experiments. Interestingly, the cotransfected HeLa SS6 cells died before GFP expression was detected indicating very rapid induction of cell death, in agreement with published data for HeLa cells [23]. Time-course experiments confirmed this observation: Light microscopic analyses showed apoptotic HeLa SS6 cells already 10 hours after transfection (data not shown)

\section{Induction of cell death by tBid in the suicide vector pLtBid(INS) ${ }_{2} R$ strongly depends on the presence of both HIV-1 Tat and Rev}

First, we characterized the control vector pLRed(INS) ${ }_{2} \mathrm{R}$ (Figure 1B) in transiently transfected HeLa SS6 cells or in HeLa-Tat cells, constitutively expressing the HIV-1 Tat protein. DsRed was not expressed in the absence of Tat and Rev or in the presence of only one of both viral proteins (Figures $1 \mathrm{C}$ and 2A). Co-transfection of HeLa SS6 cells with the plasmids pLRed(INS) ${ }_{2} \mathrm{R}, \mathrm{pCMV}$-tat and -rev led in $6.5 \%$ of the cells to a $>10$-fold induction of dsRed fluorescence after 24 hours (Figure 2A), this number further increased to $>40 \%$ during the next 24 hours (data not shown). In HeLa cells stably expressing the HIV-1 Tat protein, dsRed fluorescence increased up to three orders of magnitude in the presence of both Tat and Rev (Figure 1C) [40]. As already observed in pEGFP-C1-transfected HeLa SS6 cells, it takes about 48 hours to reach sufficient dsRed expression. Next, we determined the number of dead cells in HeLa SS6 cells transfected with the control vector pLRed(INS) ${ }_{2} \mathrm{R}$ alone or in combination with pCMV-tat and/or -rev. All cells transfected displayed similar morphology (Figure 2B, top row of panels), and the number of dead cells determined by propidium iodide staining was in the range of 2.7$7.2 \%$ and, thus, similar in all transfections (Figure 2C).

We then replaced the reporter gene dsRed with tBid to generate the suicide vector pLtBid(INS) ${ }_{2} \mathrm{R}$ (Figure 1B). HeLa SS6 cells were transfected with this vector and cotransfected with pCMV-tat and/or -rev. 24 hours after transfection, light microscopic analysis showed that the morphology of the transfected cells represented living cells in all transfections containing the suicide vector 

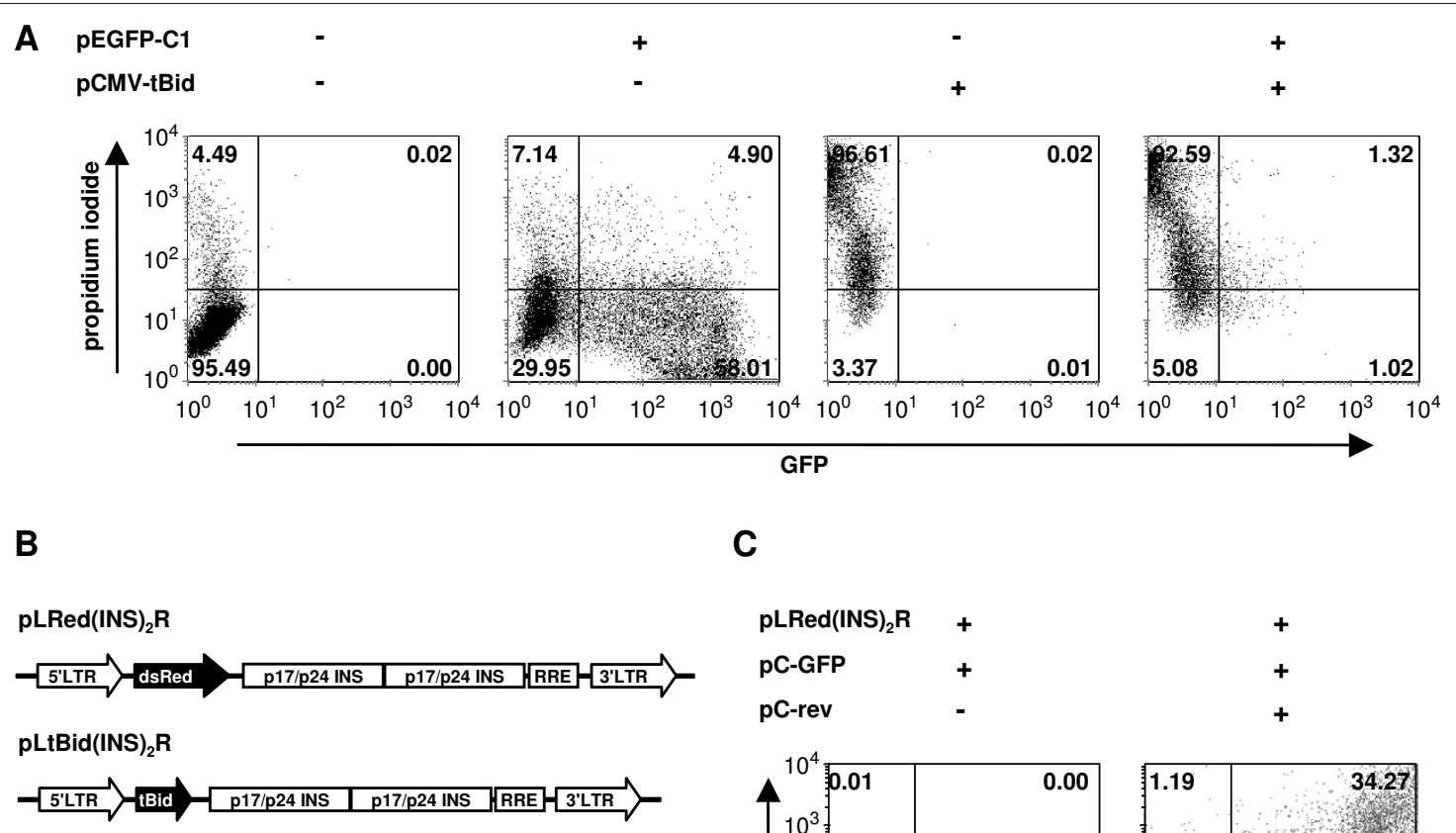

C
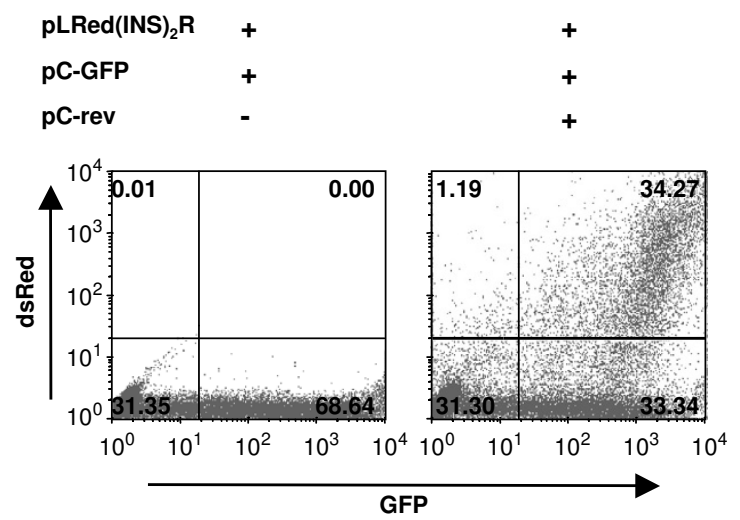

Figure 1 Induction of cell death by tBid in HeLa SS6 cells and general architecture of the control vector pLRed(INS) ${ }_{2} R$ and the suicide vector pLtBid(INS) ${ }_{2}$ R. (A) Hela SS6 cells were transfected with pCMV-tBid and/or pEGFP-C1. 24 hours after transfection, cell death and GFP expression were determined by FACS analysis. Shown is a representative example of three independent experiments. Percentages of GFPpositive, PI-positive and GFP + Pl-positive cells are given for each quadrant. (B) Schematic representation of pLRed(INS) $)_{2} R$ and pLtBid(INS) ${ }_{2} R$. p17/p24 INS = INS-containing region from gag; RRE = Rev-responsive element. (C) FACS analysis of dsRed expression from pLRed(INS) ${ }_{2} R$ without (left) and with Rev (right) in HeLa-Tat cells constitutively expressing Tat. A plasmid, driving GFP expression under the control of the CMV promoter, was transfected as a transfection/expression control (modified from reference [40]).

pLtBid(INS) ${ }_{2} \mathrm{R}$ alone or in combination with either pCMV-tat or -rev. However, co-transfection of both pCMV-tat and -rev together with the suicide vector pLtBid(INS) ${ }_{2} \mathrm{R}$ rapidly induced microscopic signs of cell death like cell shrinkage and rounding (Figure 2B, lower row of panels). Cell death was also quantified by staining the cells with propidium iodide 24 hours after transfection. $4.5 \%$ of the cells were dead in cell cultures transfected only with the suicide vector pLtBid(INS) ${ }_{2} \mathrm{R}$, a number similar to the control transfections. Thus, induction of cell death was not observed in the absence of Tat and Rev despite using the very sensitive HeLa SS6 cell line. We also did not observe any increase in cell death induction 48 or 72 hours after transfection (data not shown). Expression of Rev alone did not lead to induction of cell death by tBid. Here, only $5.7 \%$ of the cells stained positive with propidium iodide (Figure $2 \mathrm{C}$ ). The presence of Tat moderately induced cell death in the absence of $\operatorname{Rev}$ (13\%, Figure 2C). Taken together, these results show that this vector is not leaky. Only expression of both HIV-1 regulatory proteins Tat and Rev strongly induced cell death in co-transfected HeLa SS6 cells. Here, $86 \%$ of the cells were dead 24 hours after transfection (Figure $2 \mathrm{C}$ ). At this same time point, only $6.5 \%$ of the cells were dsRed-positive when co-transfected with the control vector pLRed(INS) ${ }_{2} \mathrm{R}$ and pCMV-tat plus -rev indicating that very low amounts of tBid are sufficient to induce cell death.

\section{Co-transfection of pLtBid(INS) ${ }_{2} \mathrm{R}$ and pNL4-3-Nef-IRES-GFP leads to rapid induction of cell death before virus particles are produced}

To investigate whether HeLa SS6 cells transfected with the suicide vector $\mathrm{pLtBid}(\mathrm{INS})_{2} \mathrm{R}$ undergo cell death before infectious HIV-1 virions are generated and released, we co-transfected cells with the suicide vector pLtBid(INS) ${ }_{2} \mathrm{R}$ and the HIV-1 full-length clone pNL4-3/ GFP. The latter construct contains a GFP reporter gene 


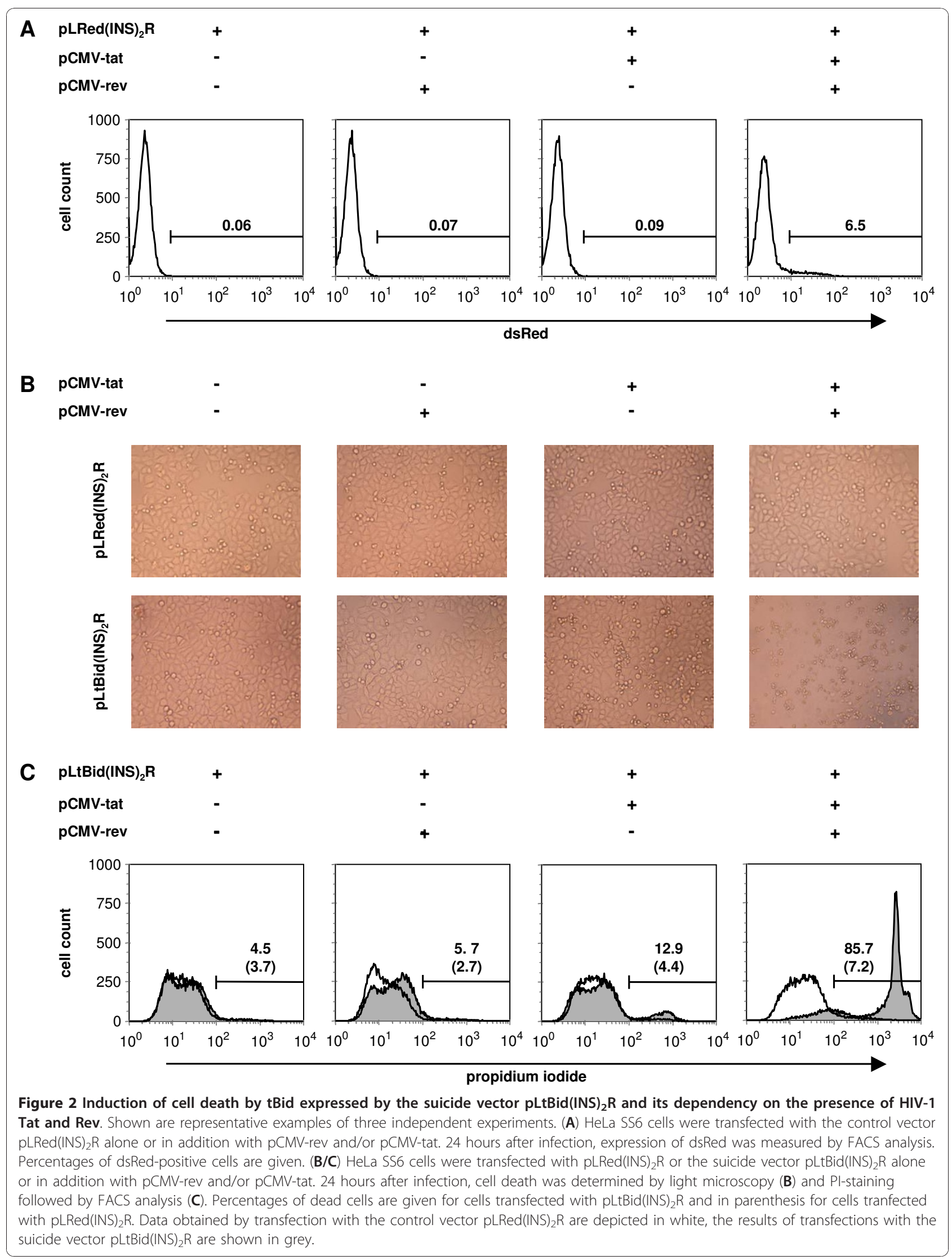


within the open reading frame for Nef, ensuring that GFP is expressed together with Tat and Rev early in the HIV-1 life cycle. $27 \pm 3.3 \%$ of the HeLa SS6 cells cotransfected with pNL4-3/GFP and the control vector pLRed(INS) ${ }_{2} \mathrm{R}$ expressed GFP 24 hours after transfection in three independent experiments. These transfection efficiencies are similar to control experiments performed with a GFP-expressing plasmid of approximately the same size as pNL4-3/GFP ( 15 kb) (data not shown). In contrast, only $1.0 \pm 0.3 \%$ of the HeLa SS6 cells co-transfected with pNL4-3/GFP and the suicide vector pLtBid (INS) ${ }_{2} \mathrm{R}$ expressed GFP 24 hours after transfection suggesting that cell death is induced in the co-transfected HeLa SS6 cells before green fluorescence becomes detectable. The approximately 28 -fold difference in the amount of GFP-positive cells between both transfections is highly significant with a p-value $<0.001$ (Figure 3A). Transfections using only pNL4-3/GFP revealed similar results as co-transfections with the control vector pLRed $(\mathrm{INS})_{2} \mathrm{R}$ and pNL4-3/GFP (Figure 3A). We also collected cell-free supernatant daily for 4 days after transfection and analyzed the production of virus particles by determining the content of viral p24 in the supernatant. In the presence of the control vector pLRed(INS) ${ }_{2} \mathrm{R}$, the replication kinetics of HIV-1 NL4-3 were similar to those observed in HeLa SS6 cells only transfected with pNL4-3/GFP (Figure 3B). However, we were not able to detect p24 in any supernatant from a cell culture cotransfected with the suicide vector $\mathrm{pLtBid}(\mathrm{INS})_{2} \mathrm{R}$ and pNL4-3/GFP within fours days after co-transfection agreeing with the results obtained by measuring GFP expression in those cells.

To determine if the inhibition of virus replication is due to the rapid induction of cell death, we measured the percentage of dead cells 24 hours after transfection with pNL4-3/GFP or co-transfections with pNL4-3/GFP and either the control vector pLRed(INS) ${ }_{2} \mathrm{R}$ or the suicide vector $\mathrm{pLtBid}(\mathrm{INS})_{2} \mathrm{R}$. Cells were stained with the dead cell discrimination reagent. On average, $8.1 \pm 1.2 \%$ and $11 \pm 1.5 \%$ of the cells transfected with pNL4-3/GFP or co-transfected with pNL4-3/GFP and the control vector pLRed(INS) ${ }_{2} \mathrm{R}$, respectively, were dead 24 hours after transfection (Figure $3 \mathrm{C}$ ). A strongly significant increase in the percentage of dead cells was observed in HeLa SS6 cells 24 hours after co-transfection with pNL4-3/GFP and the suicide vector $\mathrm{pLtBid}(\mathrm{INS})_{2} \mathrm{R}$ (average: $45 \pm 4.5 \%, \mathrm{p}<0.001$, Figure $3 \mathrm{C}$ ). This clearly demonstrates that the expression of Tat and Rev from transfected HIV-1 DNA induces cell death rapidly and efficiently enough to prevent the production of new virus particles.

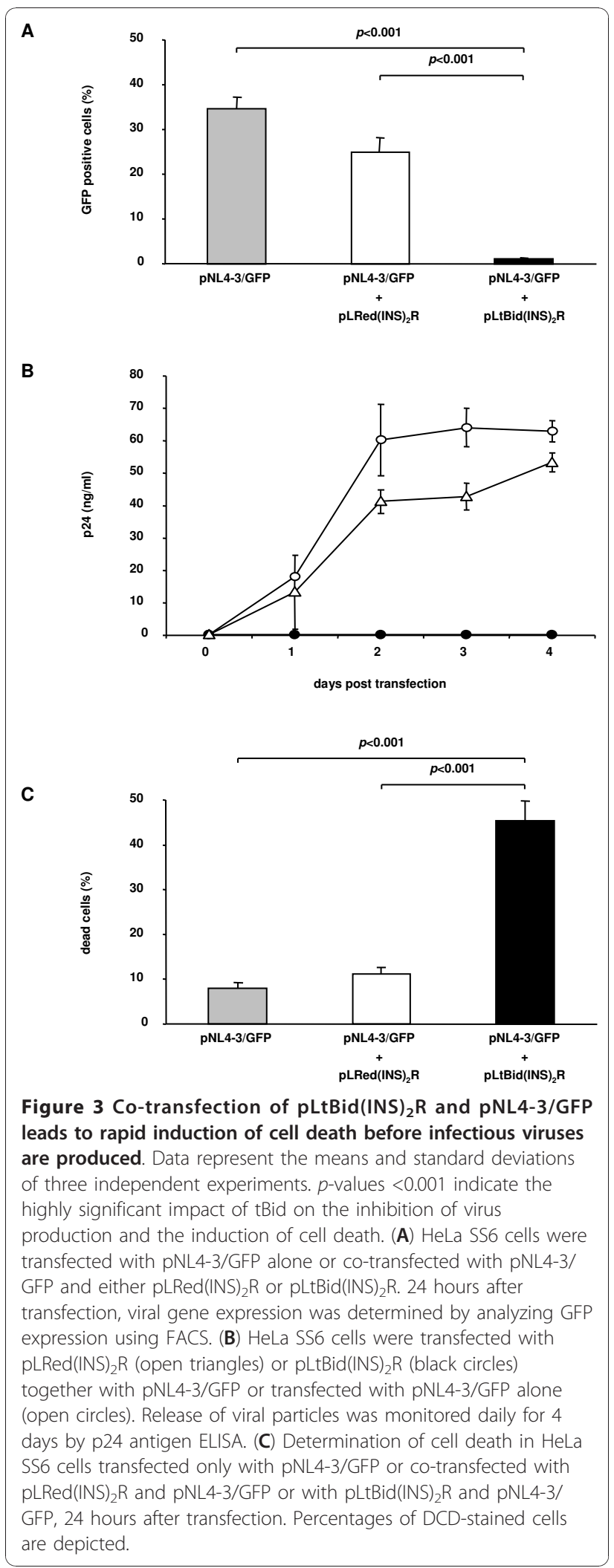


Inhibition of HIV-1 NL4-3 replication in pLtBid(INS) ${ }_{2} \mathrm{R}-\mathrm{CD} 4$ transfected HeLa SS6 cells

Next, we investigated the functionality of our suicide vector pLtBid(INS) ${ }_{2} \mathrm{R}$ in the context of infectious HIV-1 particles. We introduced a CMV-expressed cDNA for the HIV-1 receptor CD4 into the suicide vector pLtBid(INS) ${ }_{2} \mathrm{R}$ obtaining pLtBid(INS) ${ }_{2} \mathrm{R}-\mathrm{CD} 4$. We transfected HeLa SS6 cells, which do not physiologically express the CD4 receptor with pLtBid(INS) ${ }_{2} \mathrm{R}-\mathrm{CD} 4$. This guarantees that only cells containing the suicide vector would be permissive for HIV-1 infection, thereby eliminating the possibility of virus replication in HeLa SS6 cells only transfected with a CD4 expression plasmid if a co-transfection approach using separate plasmids would have been used. pLRed(INS) ${ }_{2} \mathrm{R}-\mathrm{CD} 4$ was constructed as control vector. HeLa SS6 cells were infected with HIV-1 NL4-3 36 hours after transfection and viral p24 was measured daily in cell-free supernatants. To control for transfection efficiency and consistency, CD4 expression was measured 24 hours after infection by FACS analysis. pLRed(INS) ${ }_{2} \mathrm{R}$ CD4- and pLtBid(INS) ${ }_{2} \mathrm{R}-\mathrm{CD} 4$ transfected HeLa SS6 cells expressed similar levels of CD4 (Figure 4A). HIV-1 NL43 did not replicate in mock-transfected or untransfected HeLa SS6 cells (Figure 4B; data not shown). HIV-1 NL43 replication was inhibited by $75 \pm 6.1 \%$ on day 3 and 69 $\pm 6.4 \%$ on day 4 after infection compared to virus replication in HeLa SS6 cells transfected with the control vector pLRed(INS) ${ }_{2}$ R-CD4 (Figure 4B,C). We also quantified the amount of dead cells 48 hours after infection, i.e., 84 hours after transfection. $28 \pm 0.5 \%$ of the mocktransfected and $33 \pm 1.3 \%$ of the pLRed(INS) ${ }_{2} \mathrm{R}-\mathrm{CD} 4$ transfected HeLa SS6 cells were dead (Figure 4D). These percentages of dead cells are higher compared to the amount of dead cells in our previous HeLa SS6 transfections using pLRed(INS) ${ }_{2} \mathrm{R}$ and pNL4-3/GFP. This is mainly due to the different time points chosen to measure the proportion of dead cells (24 versus 84 hours after transfection). An even higher increase in the number of dead cells was observed in pLtBid(INS) ${ }_{2}$ R-CD4 transfected HeLa SS6 (46 $\pm 5.0 \%$, Figure 4D) suggesting that those cells were also dying due to the induction of tBid expression by HIV-1 NL4-3. This high amount of dead cells was significantly different compared to mocktransfected cells $(\mathrm{p}=0.04)$; the difference was not significant compared to pLRed(INS) $)_{2}$ R-CD4-transfected HeLa SS6 cells $(\mathrm{p}=0.08$, Figure 4D). However, the latter is caused by cytopathic effects resulting from the HIV-1 infection itself, which would also explain the higher amount of dead cells in pLRed(INS) ${ }_{2}$ R-CD4 transfected HeLa SS6 cells compared to mock-transfected cells.

\section{Discussion}

Despite several set-backs, the development of suicide vector systems can still be a promising approach for gene therapy of HIV-1 infection [5,41]. They can be used to reduce viral burden by killing infected, virusproducing cells $[9,21]$ and to target and eliminate the reservoir of latent HIV-1 [5]. They might even be used to modify stem cells prior to their transplantation into the patient $[42,43]$. These booby-trapped hematopoietic cells would commit suicide upon infection by HIV-1, thereby interrupting the viral replicative cycle and reducing viral load. However, for such an approach to function, several requirements have to be fulfilled. First, the suicide vector must be strongly HIV-1 dependent without compromising the rapid induction of the suicide gene by the viral proteins. Second, the suicide gene itself has to be fast and efficient in its induction of cell death, to ensure target cell elimination before infectious virus particles are generated. Third, the suicide gene should not be immunogenic. Fourth, the suicide system has to be delivered efficiently to the HIV-1 target cells. So far, no published system fulfills all of these necessities. In our proof-of-concept study, we addressed the first three requirements.

The suicide vector $\mathrm{pLtBid}(\mathrm{INS})_{2} \mathrm{R}$ contains the HIV-1 LTRs, thus, expression of tBid depends on HIV-1 Tat. However, the HIV-1 LTR alone would lead to unspecific expression of tBid as frequently observed using solely HIV-1 LTR-based vector systems $[21,32,44]$. The RRE present in the suicide vector pLtBid(INS) ${ }_{2} \mathrm{R}$ reduces this leakiness, because expression now depends on both Tat and $\operatorname{Rev}[9,33,34,45]$. In addition, the suicide vector pLtBid(INS) ${ }_{2}$ R comprises two INS-containing regions of the HIV-1 gag gene. They increase the dependency on Rev, thereby reducing basal activity even further $[40,46,47]$. We tested the control vector pLRed(INS) ${ }_{2} \mathrm{R}$ in HeLa SS6 cells showing that the expression of dsRed is strongly dependent on the simultaneous presence of Tat and Rev. We observed no leakiness of the suicide vector pLtBid(INS) ${ }_{2} \mathrm{R}$ in the very sensitive cell line HeLa SS6 transfected only with pLtBid(INS) ${ }_{2} \mathrm{R}$ or co-transfected with pCMV-rev. The presence of Tat alone slightly induced the expression of tBid followed by induction of cell death in a small number of cells. However, only the presence of both Tat and Rev significantly enhanced the induction of cell death introduced by tBid showing that the system is not leaky and that it strongly depends on the HIV-1 proteins Tat and Rev. It is promising that no leakiness was observed in cells stably transfected with the control vector pLRed(INS) $)_{2}$ R for more than 3 months. In addition, dsRed expression was still inducible by HIV-1 Tat and Rev after 3 months [48].

The human pro-apoptotic protein tBid is the effector molecule of our suicide vector pLtBid(INS) ${ }_{2}$ R. tBid fulfills several qualifications of a suitable suicide protein: i) cell death is induced within hours after expression of tBid, ii) tBid is efficient in very low concentrations [23], 

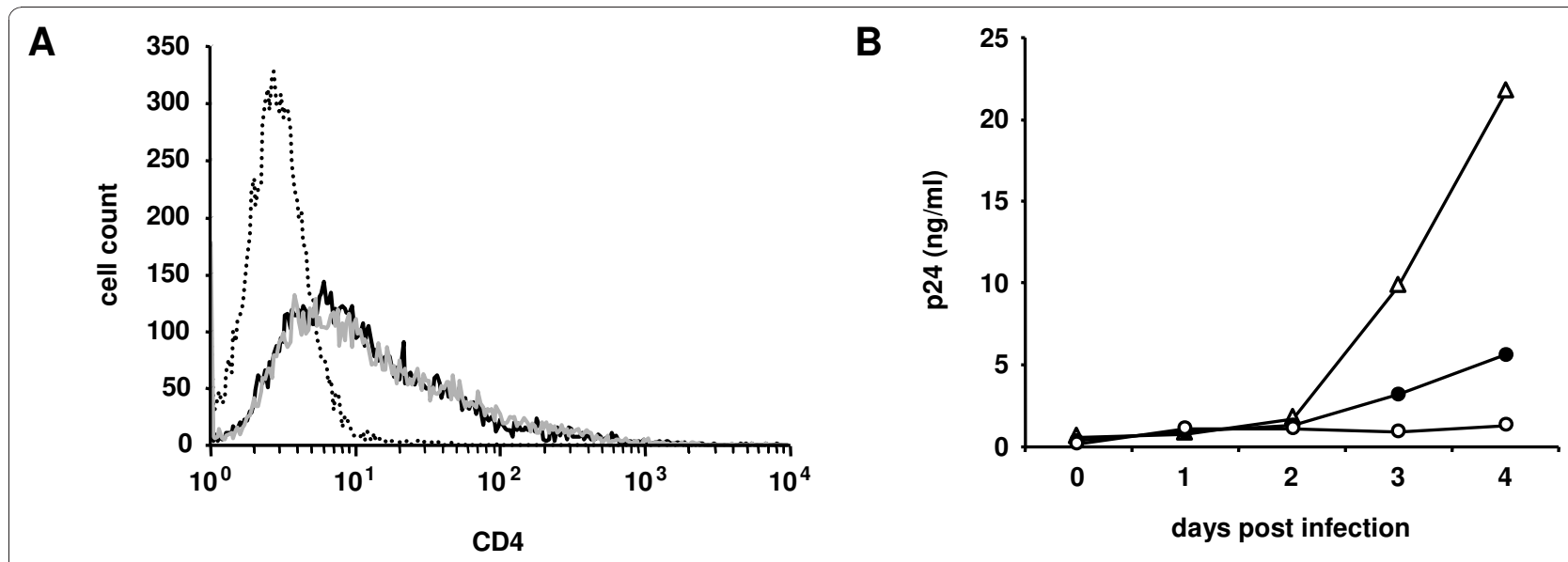

C

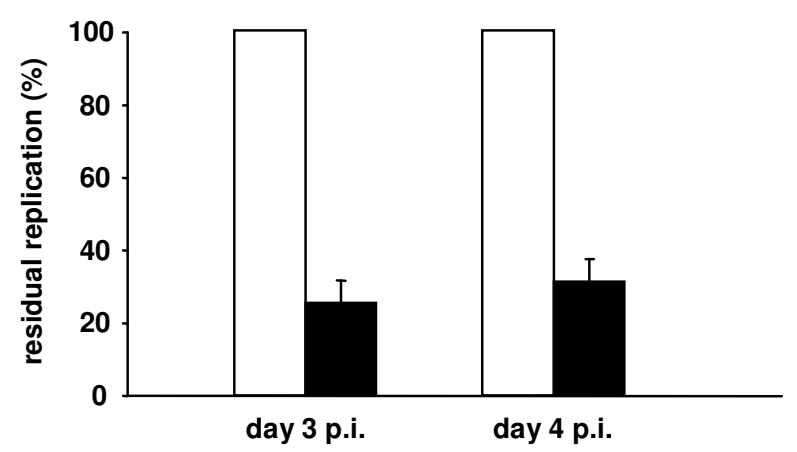

D

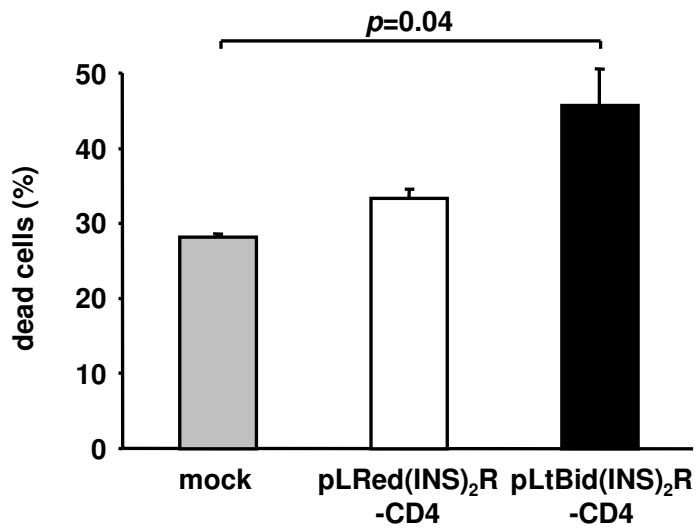

Figure 4 Inhibition of HIV-1 NL4-3 replication in pLtBid(INS) ${ }_{2}$ R-CD4 transfected HeLa SS6 cells. HeLa SS6 cells were transfected with the control vector pLRed(INS) 2 R-CD4 or the suicide vector pLtBid(INS) 2 R-CD4. 36 hours after transfection, HeLa SS6 cells were infected with HIV-1 NL4-3. The data shown are from two independent experiments, each performed in duplicate. (A) CD4 expression was determined by FACS analysis 24 hours after infection with HIV-1 NL4-3 in mock transfected (dotted line), pLRed(INS) ${ }_{2}$ R-CD4 transfected (black line), and pLtBid(INS) 2 RCD4 transfected (grey line) HeLa SS6 cells. (B) Release of viral particles was determined by p24-ELISA using cell-free supernatants of HIV-1 NL4-3 infected HeLa SS6 cells transfected with pLRed(INS) ${ }_{2}$ R-CD4 (open triangles), pLtBid(INS) ${ }_{2}$ R-CD4 (black circles), or mock controls (open circles). Shown is one representative assessment. (C) Depicted is the residual replication of HIV-1 NL4-3 at days 3 and 4 post infection in pLtBid(INS) 2 RCD4 transfected HeLa SS6 cells (black) as measured by p24 antigen ELISA, background subtracted, and normalized to p24 values obtained in pLRed(INS) ${ }_{2}$ R-CD4 transfected HeLa SS6 cells (white). (D) Determination of cell death in HeLa SS6 cells in mock transfected (grey), pLRed(INS) 2 RCD4 transfected (white), and pLtBid(INS) 2 R-CD4 transfected (black bar) cells $48 \mathrm{~h}$ after infection with HIV-1 NL4-3. Percentages of DCD-stained cells are depicted.

iii) it is not immunogenic as, for instance, viral suicide proteins [11,32], and iv) it has been successfully applied as suicide protein in a gene therapeutic approach where breast cancer cells were specifically killed by tBid in vitro [24]. We observed rapid induction of cell death in HeLa SS6 cells within 24 hours after transfection of pCMV-tBid. Similar kinetics and efficacies had previously been shown in several cell lines $[23,25,49]$ including Jurkat $\mathrm{T}$ lymphocytes [50].

We tested the cell death inducing properties of our suicide vector pLtBid(INS) ${ }_{2} \mathrm{R}$ with respect to HIV-1 using different experimental approaches. First, we cotransfected cells with the suicide vector $\mathrm{pLtBid}(\mathrm{INS})_{2} \mathrm{R}$ and the full-length HIV-1 clone pNL4-3/GFP. A few hours after transfection, before infectious HIV-1 particles were generated, the cells started to die. Here, no release of virus particles was observed as revealed by p24 ELISA. Second, cells were transfected with the suicide vector pLtBid(INS) ${ }_{2}$ R-CD4 and infected with infectious HIV-1 NL4-3. Virus replication was strongly reduced and the amount of dead cells increased compared to HeLa SS6 cells transfected with the control vector pLRed(INS) ${ }_{2} \mathrm{R}-\mathrm{CD} 4$. Although we have not measured tBid directly in dying cells due to the very low amounts of tBid sufficient to induce apoptosis [23,49], which makes it very difficult to detect tBid with conventional detection methods, we are convinced that tBid expression induced cell death. In all our experiments, 
we used the isogenic vector pLRed(INS) ${ }_{2} \mathrm{R}$ as control and we never observed any indication of increased cell death induced by dsRed.

In contrast to the co-transfection experiments using pNL4-3/GFP, the inhibition of virus particle production was incomplete when pLtBid(INS) ${ }_{2} \mathrm{R}-\mathrm{CD} 4$ transfected HeLa SS6 cells were infected with HIV-1 NL4-3. This is not due to the replacement of nef by gfp in pNL4-3/ GFP, because we obtained similar results using pNL4-3 (data not shown). Several possible reasons could explain this observation. Residual replication might be due to the long CD4 half-life of approximately 20-24 hours on the cell surface $[51,52]$ when rapidly dividing cells lose the transiently transfected suicide vector pLtBid(INS) ${ }_{2} \mathrm{R}$ CD4. We have observed that transiently transfected plasmids were not detectable anymore after a few cell divisions in HeLa SS6 cells (unpublished observations). This would lead to the presence of cells which do not contain the suicide vector pLtBid(INS $)_{2}$ R-CD4, but still exhibit sufficient amounts of CD4 to promote HIV-1 entry and replication. It is known for a $\mathrm{T}$ cell-line adapted HIV-1 strain like NL4-3 that low CD4 expression does not impair virus replication [53]. It has also been described that cells lacking the CCR5 or CXCR4 receptor can be rendered $\mathrm{CCR}^{+}$or $\mathrm{CXCR} 4^{+}$by uptake of membrane-derived microparticles from CCR5- or CXCR4-positive cells [54]. There is evidence that CD4 ${ }^{+}$ cells undergoing programmed cell death shed microparticles that carry CD4 [55], offering another possibility of how co-cultured cells not expressing the CD4 antigen themselves could become infected after CD4 uptake.

The incomplete replication suppression might also be caused by differences in the levels and kinetics of HIV-1 Tat and Rev expression in the more physiological conditions using infectious virus particles [56,57]. A critical threshold level of Rev is required for highly productive HIV-1 infection [58]. In contrast to the HIV-1 genome, pLtBid(INS) ${ }_{2} \mathrm{R}-\mathrm{CD} 4$ contains a duplication of the INS region. In the absence of Rev, gene expression of gag/ pol and env mRNA is not completely inhibited in the context of wild-type HIV-1 [59], but this INS duplication results in enhanced suppression of gene expression. Thus, it might be that a threshold level of Rev for sufficient expression of tBid was not reached in all cells by the infection. To address this concern, we are currently focusing on improving the pro-apoptotic properties of tBid by (i) introducing mutations that eliminate ubiquitin acceptor sites and thereby improve tBid's intracellular stability [60] and by (ii) modifying its $\mathrm{N}$-terminal sequence to allow myristoylation of tBid, which promotes targeting to mitochondria and enhances proapoptotic activity in cell culture [61]. A similar low efficiency was recently described for replication-competent wild-type HIV-1 virions compared to single-cycle VSV-
G pseudotyped HIV-1 virus particles in another investigation of a potential Rev-dependent suicide vector [9].

\section{Conclusions}

In summary, we have shown in three independent experimental settings that the induction of cell death by tBid in the context of our suicide vector pLtBid(INS) ${ }_{2} \mathrm{R}$ is not leaky, occurs very rapidly, and is highly dependent on HIV-1. Furthermore, the production of virus particles and virus replication is substantially inhibited in cells transfected with the suicide vectors pLtBid(INS) ${ }_{2} \mathrm{R} /$-CD4. Thus, this vector system shows promise as a gene therapy vector.

\section{Methods}

\section{Plasmid constructions}

The cDNA of tBid was cloned into pEGFP-C1 (Invitrogen, Karlsruhe, Germany) by replacing GFP by tBid, which was isolated from the plasmid pWHE171 [23] to obtain the expression plasmid pCMV-tBid. For the construction of the suicide vector, pLRed(INS) ${ }_{2} \mathrm{R}$ [40] and pCMV-tBid were restricted with NheI and MscI or EcoRV (New England Biolabs), respectively. tBid was ligated into the vector replacing dsRed. To obtain the correct amino acid sequence of $\mathrm{tBid}$, this plasmid was restricted with NheI and BssHII (NEB) and a linker was added consisting of the oligonucleotides ptBid-linker1 5'-CGCGCGGGCCGG-3' and ptBid-linker2 5'-CTAG CCGGCCCG-3' (biomers.net, Ulm, Germany). This vector is referred to as pLtBid(INS) ${ }_{2} \mathrm{R}$.

For including the HIV-1 receptor $\mathrm{CD} 4$ in the suicide vector $\mathrm{pLtBid}(\mathrm{INS})_{2} \mathrm{R}$ and the control vector $\mathrm{pLRed}$ (INS) ${ }_{2} R$, the open reading frame of the human CD4 mRNA was amplified from cDNA of $\mathrm{HeLa} \mathrm{CD} 4^{+}$cells, kindly provided by D. Kabat (Oregon Health \& Science University, Portland), using the oligonucleotides CD4 81 Hind III 5'- CGAATTCAAGCTTCAGAGGCCCTGCCATTTCTG-3' and CD41700 rc Xho I 5'- CATAGACTCGAGCACTCAACCAGTGAAGCCGG-3' (biomers.net, restriction sites are underlined). The CD4 amplicon and the expression vector pcDNA3.1 (Invitrogen) were restricted with HindIII and XhoI and ligated. The CMV-promoter-CD4 cassette was subcloned into the suicide vector $\mathrm{pLtBid}(\mathrm{INS})_{2} \mathrm{R}$ and the control vector pLRed(INS) ${ }_{2} R$ by respective restrictions with NotI and subsequent ligations. These vectors are referred to as pLtBid(INS) ${ }_{2} \mathrm{R}-\mathrm{CD} 4$ and pLRed(INS) ${ }_{2} \mathrm{R}-\mathrm{CD} 4$.

pNL4-3/GFP (contains GFP within the nef ORF) was kindly provided by F. Kirchhoff (Institute of Virology, Ulm, Germany), pCMV-tat by B. Ensoli (National AIDS Center, Rome, Italy), and pCMV-rev is a gift from J. Hauber (Heinrich-Pette Institute, Hamburg, Germany). All vector sequences were confirmed by sequencing. 


\section{Cells and transfections}

HeLa SS6 cells were maintained in Dulbecco's modified Eagle medium (DMEM, Invitrogen) supplemented with $10 \%$ heat-inactivated fetal bovine serum (Invitrogen), $170 \mathrm{mM}$ penicillin and $40 \mathrm{mM}$ streptomycin. Cells were transfected using Lipofectamine 2000 (Invitrogen) according to the manufacturer's instructions. Briefly, cells were plated in 6- or 12-well cell culture plates. When $\geq 90 \%$ confluence was reached, cells were transfected with plasmids in a total amount of 4-6 $\mu \mathrm{g}$ or 1.5$3 \mu \mathrm{g}$ per 6 - or 12 -well, respectively. Co-transfections were carried out with equal amounts of each plasmid. Light- and fluorescence microscopy was performed using an AxioVert 200 microscope (Zeiss).

\section{FACS analysis of cell death and reporter gene expression} To analyze cell death, propidium iodide (Merck) was used for all staining of non-infected cells. For safety reasons, cells potentially infected with HIV-1 were stained with the "dead cell discriminator (DCD) kit" (Miltenyi Biotec), which includes a cell fixation step according to the manufacturer's instructions. CD4 expression was analyzed by FACS using the murine anti-CD4 antibody SK3-phycoerythrin (Becton Dickinson). FACS analyses were performed using a FACSCalibur (Becton Dickinson). GFP- and dsRed expression was also determined by FACS.

\section{Viruses and infections}

HIV-1 NL4-3 virus stock was generated and characterized as previously described [62]. Cells were infected 36 hours after transfection with pLtBid(INS) ${ }_{2} \mathrm{R}-\mathrm{CD} 4$ or pLtBid(INS) ${ }_{2}$ R-CD4 with a multiplicity of infection (MOI) of 0.01. Two hours after infection, cells were washed twice with PBS and further cultivated with fresh medium. Cell-free supernatants of cell cultures transfected with pNL4-3/GFP or infected with HIV-1 NL4-3 were collected daily after infection and virus production was estimated by an in-house p24 ELISA with a detection limit of $0.125 \mathrm{ng} / \mathrm{ml}$ as previously described [63].

\section{Statistical analysis}

Differences in the induction of apoptosis, the expression of the reporter genes dsRed and GFP, or virus replication were tested for statistical significance by using a two-tailed Student's $t$-test. A p-value of $<0.05$ was considered a significant difference between two groups, a p-value below 0.001 highly significant.

\section{Note}

This work was presented in part at the Deutsch-österreichischer AIDS Kongress, 27-30 June 2007, Frankfurt, Germany (abstract F.24); 14. Jahrestagung der Deutschen
Gesellschaft für Gentherapie, 18-20 July 2007, Heidelberg, Germany (abstract); and 3. European Congress of Virology, 1-5 September 2007, Nuremberg, Germany (abstract GET006).

\section{List of abbreviations used}

CMV: cytomegalovirus; DCD: dead cell discrimination; DMEM: Dulbecco's modified Eagle's medium; EGFP: enhanced green fluorescent protein; ELISA: Enzyme Linked Immunosorbent Assay; FACS: Fluorescence Activated Cell Sorter; HIV: human immunodeficiency virus; INS: inhibitory sequences; LTR: long terminal repeat; ORF: open reading frame; RRE: Rev responsive element; VSVG: Vesicular Stomatitis Virus Glycoprotein

\section{Acknowledgements}

We thank Bernhard Fleckenstein, Birgit Wöhrl, and Wolfgang Hillen for their support. We also thank Frank Kirchhoff, Institute of Virology, Ulm, Germany, Barbara Ensoli, National AIDS Center, Rome, Italy, and Joachim Hauber, Heinrich-Pette Institute, Hamburg, Germany, for generously providing plasmids. This study was supported by the Wilhelm Sander Stiftung (grant no 2002.079.1), the Deutsche Forschungsgemeinschaft (SFBs 466 and 473, Graduiertenkolleg 1071), Swiss National Science Foundation (grant 324700 120793), and the ELAN foundation (grant no 07.07.09.1).

\section{Author details}

${ }^{1}$ University of Erlangen-Nuremberg, Institute of Clinical and Molecular Virology, Erlangen, Germany. ${ }^{2}$ University of Erlangen-Nuremberg, Department Biology, Erlangen, Germany. ${ }^{3}$ University of Zurich, University Hospital Zurich, Department of Medicine, Division of Infectious Diseases and Hospital Epidemiology, Zurich, Switzerland. ${ }^{4}$ University of Erlangen-Nuremberg, Department of Internal Medicine III, Erlangen, Germany. ${ }^{5}$ Hannover Medical School, Department of Experimental Hematology, Hannover, Germany. ${ }^{6}$ Helmholtz Zentrum München, Institute of Virology, Neuherberg, Germany.

\section{Authors' contributions}

$\mathrm{PMH}, \mathrm{KJM}$, and $\mathrm{CB}$ conceived and designed the study. $\mathrm{PMH}, \mathrm{ADH}, \mathrm{SAK}$, and PR carried out all the collection of the data and analyzed and interpreted them together with KJM and CB. JP, FdG, CD, EG, AS, and HW participated in the characterization of the apoptotic effect of tBid in cells. AS and HW provided new reagents. $\mathrm{PMH}, \mathrm{ADH}, \mathrm{KJM}$, and $\mathrm{CB}$ prepared the manuscript. All authors read and approved the final manuscript.

Received: 9 March 2010 Accepted: 11 January 2011

Published: 11 January 2011

\section{References}

1. Han JH, Kushner SA, Yiu AP, Hsiang HL, Buch T, Waisman A, Bontempi B, Neve RL, Frankland PW, Josselyn SA: Selective erasure of a fear memory. Science 2009, 323:1492-1496.

2. Du Pasquier D, Chesneau A, Ymlahi-Ouazzani Q, Boistel R, Pollet N, Ballagny C, Sachs LM, Demeneix B, Mazabraud A: tBid mediated activation of the mitochondrial death pathway leads to genetic ablation of the lens in Xenopus laevis. Genesis 2007, 45:1-10.

3. Lee P, Morley G, Huang Q, Fischer A, Seiler S, Horner JW, Factor S, Vaidya D, Jalife J, Fishman Gl: Conditional lineage ablation to model human diseases. Proc Natl Acad Sci USA 1998, 95:11371-11376.

4. Tatsumi S, Ishii K, Amizuka N, Li M, Kobayashi T, Kohno K, Ito M, Takeshita S, Ikeda K: Targeted ablation of osteocytes induces osteoporosis with defective mechanotransduction. Cell Metab 2007, 5:464-475.

5. Turner LS, Tsygankov AY, Henderson EE: StpC-based gene therapy targeting latent reservoirs of HIV-1. Antiviral Res 2006, 72:233-241.

6. Bonini C, Bondanza A, Perna SK, Kaneko S, Traversari C, Ciceri F, Bordignon C: The suicide gene therapy challenge: how to improve a successful gene therapy approach. Mol Ther 2007, 15:1248-1252.

7. Chu Y, Senghaas N, Köster RW, Wurst W, Kühn R: Novel caspase-suicide proteins for tamoxifen-inducible apoptosis. Genesis 2008, 46:530-536.

8. de Witte MA, Jorritsma A, Swart E, Straathof KC, de Punder K, Haanen JB, Rooney CM, Schumacher TN: An inducible caspase 9 safety switch can halt cell therapy-induced autoimmune disease. J Immunol 2008 180:6365-6373. 
9. Young J, Tang Z, Yu Q, Yu D, Wu Y: Selective killing of HIV-1-positive macrophages and $T$ cells by the Rev-dependent lentivirus carrying anthrolysin O from Bacillus anthracis. Retrovirology 2008, 5:36.

10. Kiuru M, Boyer JL, O'Connor TP, Crystal RG: Genetic control of wayward pluripotent stem cells and their progeny after transplantation. Cell Stem Cell 2009, 4:289-300.

11. Riddell SR, Elliott M, Lewinsohn DA, Gilbert MJ, Wilson L, Manley SA, Lupton SD, Overell RW, Reynolds TC, Corey L, et al: T-cell mediated rejection of gene-modified HIV-specific cytotoxic T lymphocytes in HIVinfected patients. Nat Med 1996, 2:216-223.

12. Kerr DJ, Young LS, Searle PF, McNeish IA: Gene directed enzyme prodrug therapy for cancer. Adv Drug Deliv Rev 1997, 26:173-184

13. Dachs GU, Hunt MA, Syddall S, Singleton DC, Patterson AV: Bystander or no bystander for gene directed enzyme prodrug therapy. Molecules 2009, 14:4517-4545.

14. Danial NN, Korsmeyer SJ: Cell death: critical control points. Cell 2004, 116:205-219.

15. Conradt B: Genetic control of programmed cell death during animal development. Annu Rev Genet 2009, 43:493-523.

16. Yang L, Cao Z, Yan H, Wood WC: Coexistence of high levels of apoptotic signaling and inhibitor of apoptosis proteins in human tumor cells: implication for cancer specific therapy. Cancer Res 2003, 63:6815-6824.

17. Del Gaizo Moore V, Letai A: Rational design of therapeutics targeting the BCL-2 family: are some cancer cells primed for death but waiting for a final push? Adv Exp Med Biol 2008, 615:159-175.

18. Vocero-Akbani AM, Heyden NV, Lissy NA, Ratner L, Dowdy SF: Killing HIVinfected cells by transduction with an HIV protease-activated caspase- 3 protein. Nat Med 1999, 5:29-33

19. Carlotti F, Zaldumbide A, Martin P, Boulukos KE, Hoeben RC, Pognonec P: Development of an inducible suicide gene system based on human caspase 8. Cancer Gene Ther 2005, 12:627-639.

20. Yip KW, Li A, Li JH, Shi W, Chia MC, Rashid SA, Mocanu JD, Louie AV, Sanchez O, Huang D, et al: Potential utility of BimS as a novel apoptotic therapeutic molecule. Mol Ther 2004, 10:533-544.

21. McCoubrie JE, Kendrick TS, Minchin RF: HIV LTR-dependent expression of Bax selectively induces apoptosis in Tat-positive cells. Biochem Biophys Res Commun 2004, 325:1459-1464.

22. Garg H, Salcedo R, Trinchieri G, Blumenthal R: Improved nonviral cancer suicide gene therapy using survivin promoter-driven mutant Bax. Cancer Gene Ther 2009.

23. Knott A, Drueppel L, Beyer T, Garke K, Berens C, Herrmann M, Hillen W: An optimized conditional suicide switch using doxycycline-dependent expression of human tBid. Cancer Biol Ther 2005, 4:532-536.

24. Kazhdan I, Long L, Montellano R, Cavazos DA, Marciniak RA: Targeted gene therapy for breast cancer with truncated Bid. Cancer Gene Ther 2006, 13:141-149.

25. Miao J, Chen GG, Chun SY, Yun JP, Chak EC, Ho RL, Lai PB: Adenovirusmediated tBid overexpression results in therapeutic effects on $\mathrm{p} 53$ resistant hepatocellular carcinoma. Int J Cancer 2006, 119:1985-1993.

26. Wang $\mathrm{K}$, Yin XM, Chao DT, Milliman CL, Korsmeyer SJ: BID: a novel BH3 domain-only death agonist. Genes Dev 1996, 10:2859-2869.

27. Li H, Zhu H, Xu CJ, Yuan J: Cleavage of BID by caspase 8 mediates the mitochondrial damage in the Fas pathway of apoptosis. Cell 1998, 94:491-501.

28. Luo X, Budihardjo I, Zou H, Slaughter C, Wang X: Bid, a Bcl2 interacting protein, mediates cytochrome $\mathrm{c}$ release from mitochondria in response to activation of cell surface death receptors. Cell 1998, 94:481-490.

29. Life expectancy of individuals on combination antiretroviral therapy in high-income countries: a collaborative analysis of 14 cohort studies. Lancet 2008, 372:293-299.

30. Phillips AN, Dunn D, Sabin C, Pozniak A, Matthias R, Geretti AM, Clarke J, Churchill D, Williams I, Hill T, et al: Long term probability of detection of HIV-1 drug resistance after starting antiretroviral therapy in routine clinical practice. AIDS 2005, 19:487-494.

31. Adelson ME, Martinand-Mari C, lacono KT, Muto NF, Suhadolnik RJ: Inhibition of human immunodeficiency virus (HIV-1) replication in SupT1 cells transduced with an HIV-1 LTR-driven PKR cDNA construct. Eur J Biochem 1999, 264:806-815.

32. Hamouda T, McPhee R, Hsia SC, Read GS, Holland TC, King SR: Inhibition of human immunodeficiency virus replication by the herpes simplex virus virion host shutoff protein. J Virol 1997, 71:5521-5527.
33. Curiel TJ, Cook DR, Wang Y, Hahn BH, Ghosh SK, Harrison GS: Long-term inhibition of clinical and laboratory human immunodeficiency virus strains in human T-cell lines containing an HIV-regulated diphtheria toxin A chain gene. Hum Gene Ther 1993, 4:741-747.

34. Ragheb JA, Couture L, Mullen C, Ridgway A, Morgan RA: Inhibition of human immunodeficiency virus type 1 by Tat/Rev-regulated expression of cytosine deaminase, interferon alpha2, or diphtheria toxin compared with inhibition by transdominant Rev. Hum Gene Ther 1999, 10:103-112.

35. Agarwal S, Nikolai B, Yamaguchi T, Lech P, Somia NV: Construction and use of retroviral vectors encoding the toxic gene barnase. Mol Ther 2006, 14:555-563.

36. Caruso M, Klatzmann D: Selective killing of CD4 + cells harboring a human immunodeficiency virus-inducible suicide gene prevents viral spread in an infected cell population. Proc Natl Acad Sci USA 1992, 89:182-186.

37. Marcello A, Giaretta I: Inducible expression of herpes simplex virus thymidine kinase from a bicistronic HIV1 vector. Res Virol 1998, 149:419-431.

38. Muesing MA, Smith DH, Capon DJ: Regulation of mRNA accumulation by a human immunodeficiency virus trans-activator protein. Cell 1987, 48:691-701.

39. Zapp ML, Green MR: Sequence-specific RNA binding by the HIV-1 Rev protein. Nature 1989, 342:714-716.

40. Wolff $H$, Brack-Werner R, Neumann M, Werner T, Schneider R: Integrated functional and bioinformatics approach for the identification and experimental verification of RNA signals: application to HIV-1 INS. Nucleic Acids Res 2003, 31:2839-2851.

41. Wolkowicz R, Nolan GP: Gene therapy progress and prospects: novel gene therapy approaches for AIDS. Gene Ther 2005, 12:467-476.

42. Rossi JJ, June CH, Kohn DB: Genetic therapies against HIV. Nat Biotechnol 2007, 25:1444-1454.

43. Schambach A, Baum C: Clinical application of lentiviral vectors - concepts and practice. Curr Gene Ther 2008, 8:474-482.

44. Bednarik DP, Mosca JD, Raj NB, Pitha PM: Inhibition of human immunodeficiency virus (HIV) replication by HIV-trans-activated alpha 2interferon. Proc Natl Acad Sci USA 1989, 86:4958-4962.

45. Wu Y, Beddall MH, Marsh JW: Rev-dependent lentiviral expression vector. Retrovirology 2007, 4:12

46. Kramer-Hammerle S, Ceccherini-Silberstein F, Bickel C, Wolff H, Vincendeau M, Werner T, Erfle V, Brack-Werner R: Identification of a novel Rev-interacting cellular protein. BMC Cell Biol 2005, 6:20.

47. Wolff $\mathrm{H}$, Hadian $\mathrm{K}$, Ziegler $\mathrm{M}$, Weierich $\mathrm{C}$, Kramer-Hammerle $\mathrm{S}$, Kleinschmidt A, Erfle V, Brack-Werner R: Analysis of the influence of subcellular localization of the HIV Rev protein on Rev-dependent gene expression by multi-fluorescence live-cell imaging. Exp Cell Res 2006, 312:443-456

48. Kremb S, Helfer M, Heller W, Hoffmann D, Wolff H, Kleinschmidt A, Cepok S, Hemmer B, Durner J, Brack-Werner R: EASY-HIT: HIV Full-Replication Technology for Broad Discovery of Multiple Classes of HIV Inhibitors. Antimicrob Agents Chemother 2010, 54:5257-5268.

49. Madesh M, Antonsson B, Srinivasula SM, Alnemri ES, Hajnoczky G: Rapid kinetics of tBid-induced cytochrome $\mathrm{c}$ and Smac/DIABLO release and mitochondrial depolarization. J Biol Chem 2002, 277:5651-5659.

50. Shelton SN, Shawgo ME, Robertson JD: Cleavage of Bid by executioner caspases mediates feed forward amplification of mitochondrial outer membrane permeabilization during genotoxic stress-induced apoptosis in Jurkat cells. J Biol Chem 2009, 284:11247-11255.

51. Rhee SS, Marsh JW: Human immunodeficiency virus type 1 Nef-induced down-modulation of CD4 is due to rapid internalization and degradation of surface CD4. J Virol 1994, 68:5156-5163.

52. Novina CD, Murray MF, Dykxhoorn DM, Beresford PJ, Riess J, Lee SK Collman RG, Lieberman J, Shankar P, Sharp PA: siRNA-directed inhibition of HIV-1 infection. Nat Med 2002, 8:681-686.

53. Kabat D, Kozak SL, Wehrly K, Chesebro B: Differences in CD4 dependence for infectivity of laboratory-adapted and primary patient isolates of human immunodeficiency virus type 1. J Virol 1994, 68:2570-2577.

54. Mack M, Kleinschmidt A, Brühl H, Klier C, Nelson PJ, Cihak J, Plachý J, Stangassinger M, Erfle V, Schlöndorff D: Transfer of the chemokine receptor CCR5 between cells by membrane-derived microparticles: a mechanism for cellular human immunodeficiency virus 1 infection. Nat Med 2000, 6:769-775. 
55. Aupeix K, Hugel B, Martin T, Bischoff P, Lill H, Pasquali JL, Freyssinet JM: The significance of shed membrane particles during programmed cell death in vitro, and in vivo, in HIV-1 infection. J Clin Invest 1997, 99:1546-1554.

56. Klotman ME, Kim S, Buchbinder A, DeRossi A, Baltimore D, Wong-Staal F: Kinetics of expression of multiply spliced RNA in early human immunodeficiency virus type 1 infection of lymphocytes and monocytes. Proc Natl Acad Sci USA 1991, 88:5011-5015.

57. Davis AJ, Li P, Burrell CJ: Kinetics of viral RNA synthesis following cell-tocell transmission of human immunodeficiency virus type 1. J Gen Virol 1997, 78:1897-1906.

58. Pomerantz RJ, Seshamma T, Trono D: Efficient replication of human immunodeficiency virus type 1 requires a threshold level of Rev: potential implications for latency. J Virol 1992, 66:1809-1813.

59. Nasioulas G, Zolotukhin AS, Tabernero C, Solomin L, Cunningham CP, Pavlakis GN, Felber BK: Elements distinct from human immunodeficiency virus type 1 splice sites are responsible for the Rev dependence of env mRNA. J Virol 1994, 68:2986-2993

60. Breitschopf K, Zeiher AM, Dimmeler S: Ubiquitin-mediated degradation of the proapoptotic active form of bid. A functional consequence on apoptosis induction. J Biol Chem 2000, 275:21648-21652

61. Zha J, Weiler S, Oh KJ, Wei MC, Korsmeyer SJ: Posttranslational Nmyristoylation of BID as a molecular switch for targeting mitochondria and apoptosis. Science 2000, 290:1761-1765.

62. Huelsmann PM, Rauch P, Allers K, John MJ, Metzner KJ: Inhibition of drugresistant HIV-1 by RNA interference. Antiviral Res 2006, 69:1-8.

63. McKeating JA, McKnight A, Moore JP: Differential loss of envelope glycoprotein gp120 from virions of human immunodeficiency virus type 1 isolates: effects on infectivity and neutralization. J Virol 1991, 65:852-860.

doi:10.1186/1472-6750-11-4

Cite this article as: Huelsmann et al.: A suicide gene approach using the human pro-apoptotic protein tBid inhibits HIV-1 replication. BMC Biotechnology 2011 11:4.

\section{Submit your next manuscript to BioMed Central and take full advantage of:}

- Convenient online submission

- Thorough peer review

- No space constraints or color figure charges

- Immediate publication on acceptance

- Inclusion in PubMed, CAS, Scopus and Google Scholar

- Research which is freely available for redistribution

Submit your manuscript at www.biomedcentral.com/submit
Biomed Central 